\title{
Abordagem antropológica para avaliação de políticas sociais*
}

\author{
An anthropological approach to the evaluation of social policies
}

\author{
Maria Cecilia de Souza Minayo* *
}

\begin{abstract}
MINAYO, M.C. de S. Abordagem antropológica para avaliação de politicas sociais. Rev. Saúde públ., S.Paulo, 25: 233-8, 1991. Apresenta-se uma abordgem antropológica relativa à avaliação de programas de saúde. Destaca-se o papel da antropologia, que sai de seu âmbito tradicional de pesquisa básica, para compor, de forma interdisciplinar com a medicina social um enfoque particular de avaliação de políticas públicas e, mais estritamente, de serviços de saúde. Coloca-se a antropologia dentro de um processo social mais abrangente, ao qual serve com seus instrumentos peculiares de apreensão da realidade. Baseando-se em pesquisa empírica de avaliação da assistência primária à saúde, numa favela do Rio de Janeiro, mostra que a abordagem qualitativa na avaliação de programas de saúde pode ser uma contribuição importante que ajuda a superar as tendências positivistas do processo avaliativo e a aprofundar visão mais totalizante do fenômeno saúde-doença.
\end{abstract}

Descritores: Avaliação de programas. Antropologia. Política de saúde.

\section{Introdução}

O presente artigo traz o debate no fórum, tanto da antropologia como da medicina social a utilização da abordagem antropológica para avaliação de programas de saúde. O principal ponto a ser sublinhado é que, na proposta em questão, a Antropologia sai de seu campo tradicional de pesquisa básica para se colocar, de forma interdisciplinar, com a medicina social e sob o enfoque da avaliação de políticas sociais. Portanto, ela propõe aqui o caráter prioritário de geração de teoria (ainda que o faça concomitantemente). Coloca-se a serviço de um processo social mais abrangente, cujo enfoque é dado pelo programa a ser avaliado, e ao qual serve com seus instrumentos peculiares de apreensão da realidade.

Objetiva-se no presente trabalho, mostrar que o encontro entre a antropologia, as politicas de saúde e as propostas teóricas de avaliação constitui-se de maneira promissora, embora não neutra ou insenta de contradições. A atividade da pesquisa é marcada durante toda a sua realização pelo quadro teórico que o pesquisador

* Apresentado no XII Congresso Internacional de Antropologia, em Zagreb, luguslávia, em 1988.

** Departamento de Ciências Sociais da Escola Nacional de Saúde Pública da Fundação Oswaldo Cruz - Rio de Janeiro, RJ - Brasil.

Separatas/Reprints: M.C. de S. Minayo - Rua Leopoldo Bulhð̌s, 1480/304 - 21041 - Rio de Janeiro, RJ - Brasil. adota, por sua visão do mundo e compromisso social assim como pelos limites do conhecimento, próprios de seu tempo. Apesar disso, a proposta da abordagem antropologica para avaliação de programas de saúde coloca nas mãos daqueles que lidam com a Saúde Pública uma oportunidade para rever as tendências positivistas que têm dominado as investigações no campo epidemiológico e desta forma, tentar uma visão mais totalizante do fenômeno saúde-doença.

\section{A Abordagem Antropológica a Serviço da Avaliação em Saúde}

A importância da antropologia para a compreensão do fenômeno saúde-doença é incontestável. Junto com os dados quantitativos e com o conhecimento técnico-científico das doenças, qualquer ação de prevenção, tratamento ou de planejamento de saúde necessita levar em conta valores, atitudes e crenças de uma população. A doença é tanto um fato clínico quanto um fenômeno sociológico. Ela exprime hoje e sempre um acontecimento biológico e individual e também uma angústia que pervaga o corpo social, confrontado com as turbulências do homem enquanto ser total. À medida que cristaliza e simboliza as maneiras como a sociedade vivencia coletivamente seu medo da morte e seus limites frente ao mal, a doença importa tanto por seus efeitos imaginários: ambos são reais do ponto de vista antropológico. A doença é uma realidade construída e o doente é um personagem social. 
Portanto, tratar o fenômeno saúde-doença unicamente com os instrumentos anátomo-fisiológicos da medicina ou apenas com as medidas quantitativas da epidemiologia clássica constitui uma miopia frente ao social e uma falha no recorte da realidade a ser estudada.

Do ponto de vista antropológico, estudos (Mauss $^{9}$; Lévy-Strauss ${ }^{7}$; Douglas ${ }^{4}$ tem mostrado que os fenômenos saúde-doença informam sobre:

a) a visão de mundo do grupo social;

b) as atitudes coletivas face a infelicidade dominadora;

c) o rompimento do indivíduo com as normas e regras de sua sociedade, freqüentemente traduzidas em códigos morais e religiosos;

d) o encontro do homem com o que considera "infeliz" e "alienante" em sua sociedade.

Apesar de incontestável importância da antropologia, seu encontro com a medicina tem se dado em condições de subsidiariedade. Vários estudos a respeito da medicina social vêm registrando, de forma crítica, tanto a atuação dos antropólogos como seu lugar no campo da saúde. (Estrella ${ }^{6}$, 1985; Nunes $^{13}$, 1985; Commaroff $^{3}$, 1978). As questões mais freqüentemente colocadas são de duas naturezas:

a) de que o trabalho antropológico é uma atividade extremamente minuciosa, dispendiosa, pouco prática, inviabilizando-se, desta forma, a sua utilização no campo da saúde. Certamente essa observação procede em parte. A antropologia enquanto disciplina básica gera teoria e conhecimento não imediatamente referidos à prática. Para dar um exemplo dos trabalhos realizados sobre a antropologia médica referente à classe trabalhadora urbana no Brasil, todos de que temos conhecimento foram realizados no âmbito da academia. (Loyola ${ }^{8}, 1983$; Montero ${ }^{12}$, 1985; Duarte $\left.{ }^{5}, 1986\right)$. No entanto, ninguém que trabalha na área da medicina social, no país, hoje pode desconhecer o valor desses estudos na sua capacidade de desvendamento do real. São contribuições básicas tanto para a formação de sanitaristas quanto para a fundamentação de programas de saúde.

b) Outra crítica mais freqüente é de que a antropologia realiza uma tarefa subordinada, colocando-se a serviço das concepções hegemônicas da medicina legitimada. Chamada a explicar peculiaridades culturais ou para realizar levantamentos preliminares à aplicação de programas de sáude pública, a antropologia tem sido acusada de fornecer os instrumentos culturais para a manipulação e o controle do Estado sobre grupos sociais específicos. Realizando estudos sobre concepções indígenas, do campesinato ou das camadas de trabalhadores urbanos-imigrantes e de baixa renda a Antropologia é apontada como cúmplice da medicina oficial na imposição de seus códigos. (Estrella 6 , 1985).

Essa crítica certamente tem sua parte de razão, porque realmente a antropologia tem servido de estratégia para políticas "colonialistas" das mais diferentes espécies e aquela que estuda os fenômenos saúde-doença não constitui exceção. Estrella ${ }^{6}$ (1985) chama atenção para várias formas de atuação de antropólogos na América Latina que justificam a acusação. No entanto, é necessário não confundir "colonialismo" com interesses reais dos grupos mais desfavorecidos sócioeconomicamente em nossa sociedade. Cremos que é tanto sua quanto nossa vontade, expressa e tácita, diminuir os índices de mortalidade, prevenir as doenças e promover a saúde. Partimos do princípio de que as aquisições da chamada "medicina científica" são um patrimônio da sociedade, da qual fazem parte todos os grupos sociais, toda a humanidade. Lutar contra a discriminação e a desigualdade na distribuição desse bem social faz parte do conceito de saúde como nos adverte Belinguer ${ }^{1}$ (1978)

"Por consciência sanitária entendo
a tomada de consciência de que a
saúde é um direito da pessoa e um
interesse da comunidade. Mas co-
mo esse direito é sufocado e este in-
teresse é descuidado, consciência sa-
nitaria é a ação individual e coleti-
va para alcançar este objetivo".

Ora, tal observação não legitima, do nosso ponto de vista, a destruição dos valores culturais dos grupos sociais pela imposição de códigos da medicina oficial. Pelo contrário, a compreensão da visão do mundo dos diferentes segmentos da sociedade pode ter outro destino que não seja o serviço à dominação, quando eles próprios passam a ser levados em conta na formulação das políticas, na sua gerência e na sua avaliação.

Portanto, contra o ponto de vista "legitimador e utilitário" (Estrella $\left.{ }^{6}, 1985\right)$, a oposição não pode ser a visão "fenomenológica" da recriação do mundo ideal dos atores sociais com seus valores, atitudes e hábitos intocados. E uma proposta que desconhece as contradições que penetram a vida social de quaisquer grupos e estratos sociais no mundo moderno. As propostas de compreensão da realidade por parte da antropologia têm que estar integradas num projeto maior de transformação, da qual ela faz parte, mas não é dona nem arauto. Seu papel (como o de qualquer ciência) não é neutro nem solitário. Seja como ciência básica, seja no campo 
da contribuição com outras práticas sociais, ela está submetida às contingências do tempo histórico e se insere nas correntes de pensamento de sua época.

Há uma pergunta que inquieta, portanto, o estudioso: há lugar para uma atividade antropológica no campo da saúde que esteja a serviço das populações-alvo dos programas governamentais?

A resposta poderia surgir dos mais diferentes enfoques. Scrimshaw e Hurtado ${ }^{14}$ (1987) tentam encaminhar essa inquietação na busca de união entre o instrumental antropológico e a avaliação de programas de saúde. Suas pesquisas já socializadas pela aplicação em diversos países e pela reflexão coletiva dos que a estão experimentando propõem um desafio:

- tornar rápidos, eficientes, de baixo custo e acessíveis os procedimentos clássicos da antropologia social para avaliação da Assistência primária à saúde.

A iniciativa acima leva a antropologia para o campo das políticas sociais e como tal, desloca o seu papel tradicional de disciplina básica para a área da pesquisa estratégica. Mais ainda, retira-a do contexto da descoberta primária para colocá-la no contexto da verificação, ainda que descoberta a verificação continuem inseparáveis tanto na pesquisa básica quanto na avaliação.

$O$ mérito principal da proposta do RAP (Rapid Assessment Procedures), por Scrimshaw e Hurtado ${ }^{14}$, é de um lado tentar padronizar metodologicamente um instrumental usado freqüentemente apenas por iniciados, e torná-lo assim acessível a um grupo maior de pesquisadores; de outro, não banalizá-lo. Isto é, torná-lo de tal forma abrangente que possa ser submetido a critérios de validação, obedecida a finalidade da investigação. A triangulação, a submissão à comunidade dos pesquisadores, os seminários de trabalho e avaliação constituem instrumentos, nada desprezíveis na construções do conhecimento, aqui preconizados. Sua experiência se dá ao nivel da assistência primária, mas pode ser extrapolada para outros programas.

O objetivo dos procedimentos antropológicos na avaliação da assistência primária são: "as crenças, as percepções a respeito da saúde, a prevenção e o tratamento das doenças e a utilização dos recursos da medicina tradicional e da medicina oficial". (Scrimshaw e Hurtado ${ }^{14}$, 1987).

O universo do trabalho de campo se limita a três categorias:

a) A comunidade - considerada aqui como uma organização social específica, ou seja, o aglomerado humano-espacial com sua dinâmica de vida, onde se realiza a pesquisa; b) A família - um número limitado de 15 a 16 crianças de 0 a 5 anos;

c) A equipe de saúde encarregada da assistência primária: agentes, corpo médico, corpo de enfermagem, assistente social, educadores de saúde.

$O$ roteiro de pesquisa tenta ser abrangente em relação ao universo:

Comunidade: características geográficas, demográficas, epidemiológicas, socioeconômicas. Recursos referentes à saúde, saneamento, educação e outros bens sociais.

Família: composição da família, condições de moradia, status sócioeconômico, concepção de saúde-doença, doenças mais comuns nas crianças e forma de tratamento; alimentação e hábitos alimentares, dietas para crianças doentes, história de morbidade da família, inventário de remédios existentes na casa, história da gravidez e dos partos das mães, uso dos recursos de saúde: oficiais e tradicionais;

Equipe de Saúde: a organização da equipe, características físicas do centro de saúde, a sala de espera, a consulta, a distribuição de alimentos e o controle do desenvolvimento infantil, farmácias e acesso aos medicamentos; o tratamento da diarréia, a reidratação oral, o programa de imunizações; a interação médico-paciente.

Do nosso ponto de vista, a análise do material coletado (primário e secundário) não pode se limitar a oferecer apenas uma visão descritiva ou fenomenológica do tema em questão. Os significados e a situação da Assistência primária à saúde, referentes ao grupo pesquisado, necessitam ser vinculados a uma totalidade maior, pois não se trata de aglomerações isoladas. Pelo contrário, essas "comunidades" constituemse de segmentos de classe com configurações específicas e participam estrutural e conjunturalmente das condições gerais de existência que o lugar no processo produtivo do país lhes confere. Noutras palavras, é necessário pensar suas condições de Saúde do ponto de vista individual ou coletivo como subordinados às formas como estão organizados no Brasil o sistema de saúde e o sistema socioeconômico.

Para dar um exemplo, nas pesquisas que realizamos (Minayo $\left.{ }^{10}, 1988\right)^{*}$, a proposta da assistência primária esbarra, para um grande número de famílias, nos níveis de miséria absoluta. Medidas assistenciais do governo se tornam praticamente ineficazes quando encontram esses

\footnotetext{
* Pesquisa realizada dentro de um trabalho da Universidade das Naçôes Unidas, para testagem do RAP (Rapid Assessment Procedures for Nutrition and Primary Health Care), finalizada em maio de 1988 e apresentada no "International Workshop on RAP - Anthropological Approaches to Programme Improvement (UNU - UNICEF FORD FOUNDATION. Zagreb, July, 1988, 18-22)'.
} 
limites estruturais. Qualquer ação transformadora, portanto, transcende às atividades preconizadas no campo estrito da saúde. Da mesma forma, o centro de saúde faz parte de um sistema político, administrativo e burocrático muito mais amplo que condiciona suas ações com normas e regras hierarquicamente superiores.

O conhecimento dessas instâncias é importante e fundamental na avaliação. Não podemos aceitar uma visão mecânica e simplista que subordina o sentido de qualquer prática apenas aos determinismos estruturais. As relaçōes sociais no interior das instituições, das classes e dos grupos são complexas, conflitivas, expressam interesses múltiplos e contraditórios. Portanto, esse marco referencial mais amplo, por si só, não dá conta da compreensão da micro-realidade: ela é específica. Porém os interesses e significados dos atores sociais a respeito de sua prática, a peculiaridade de sua visão de mundo que muda com a intervenção das propostas externas, mas que modifica também o conteúdo oficial dos programas, só pode ser entendida quando se coloca a base material estrita e ampla que lhe dá sustentação.

No que concerne ao campo das políticas sociais impõem-se algumas observações. Pesquisa em políticas públicas passou a significar, a partir da segunda Guerra Mundial, um foco de atividades científicas que têm implicações imediatas do ponto de vista da dominação e do controle do Estado. Isto é, há um interesse do Estado em conhecer, regular e controlar a sociedade civil. Trata-se, porém, de um campo de relações contraditórias e conflitivas em que os diferentes grupos sociais, através de diversas mediaçōes, expressam seus interesses específicos. O conhecimento desse fato significa concluir que as investigações no setor podem ser conduzidas em múltiplas direções.

Bulmer ${ }^{2}$ (1978), propõe para as pesquisas no setor de políticas sociais a denominação de "estratégica". Esse autor refuta a divisão tradicional entre "pesquisa pura" e "pesquisa aplicada" mostrando que o campo empírico das investigações exige uma classificação mais precisa e mais complexa. "Pura ou Básica" em oposição a "Aplicada" conota uma falsa dicotomia, na medida em que pesquisas teóricas podem ter importantes conseqüências práticas e vice-versa. $\mathrm{O}$ autor assinala cinco modalidades de pesquisa que não se contradizem, e cujos limites são dados por ênfases mais acentuadas em determinado aspecto:

a) Pesquisa básica ou pura;

b) Pesquisa estratégica;

c) Pesquisa-ação;

d) Pesquisa de inteligência;

e) Pesquisa operacional.
Por "Pesquisa Estratégica" entendemos aquela que se fundamenta nas teorias das ciências sociais, mas têm como principal objetivo esclarecer determinados aspectos da realidade para a ação das políticas públicas. Seus instrumentos são freqüentemente interdisciplinares e seus resultados se encaminham, para a solução de problemas. Ao contrário, as pesquisas básicas tradicionalmente se voltam para a construção da teoria e são marcadas pela interdisciplinaridade.

A introdução da antropologia no âmbito da saúde pública tem que incluir as características da abordagem antropológica e da pesquisa estratégica, trazendo para o campo da avaliação das políticas públicas, uma contribuição de sentido epistemológico e político.

Ao propor uma abordagem qualitativa para avaliação, a antropologia introduz de forma positiva a importância do "subjetivo" em qualquer abordagem do social, oferecendo instrumentos para sua apreensão. Desta forma, enquanto opera ao nível dos Significados a antropologia (nas suas mais diversas correntes) passa a questionar, pela contribuição que dá, os fundamentos do positivismo sociológico.

Sem negar a possibilidade de quantificar determinados dados da realidade, aponta para o problema fundamental das ciências sociais, que é o caráter específico de seu objetivo, que é sujeito e que se recusa peremptoriamente a se revelar apenas em número ou a se igualar com sua própria aparência.

É importante introduzir nos programas estabelecidos pela medicina oficial o ponto de vista dos grupos sociais-alvo, admitindo seu nível de racionalidade. Tendo como objeto-sujeito de seus estudos a cultura dos grupos dominados, em relação ao fenômeno saúde-doença, essas pesquisas contrapõem ao campo da dominação, a relativização das culturas, a lógica interna dos diferentes segmentos sociais, sua contribuição para a sociedade e os motivos de sua resistência ao que lhes é imposto. O respeito ao ponto de vista da população-alvo se dá, portanto, não como estratégia de dominação, mas para modificar os pontos de estrangulamento dos serviços a que ela tem direito e que deve reivindicar. É sobre esse objetivo que se redefine o conceito de política social: ela não é vista apenas como uma ação de estado em direção à população, mas como um direito para o qual ela deve opinar em termos de efetividade e qualidade.

Da perspectiva dos resultados da pesquisa, o material tem que estar em função do objetivo pretendido. Isto é, evitando-se a curiosidade científica como fim em si mesma, dar-se-á relevância aos estrangulamentos socioeconômicos, 
político-administrativos e de ordem ideológicoculturais que impedem o acesso da população aos benefícios da assistência primária à saúde.

Em lugar do feitiço dos números que costuma medir a eficácia dos produtos acabados nas avaliações convencionais, o estilo desta avaliação dá ênfase ao processo de aplicação dos programas e aqueles detalhes de contradição que costumam acompanhá-lo (Minayo Gomez"1, 1984). Ou seja, o processo é feito de conjunção de fatos, de experiências e implica a presença de atores e forças que lutam, se contrapõem, se aliam e assim constroem a realidade. Processo conota movimento, mudança, direção, interação e intencionalidade. Parte do pressuposto de que todo projeto humano é inconcluso e pode ser superado, portanto envolve atuação dos agentes sociais participantes e do analista do processo social. Desta forma, os resultados advindos da avaliação são um produto processual histórico, não externo, mas do grupo e pode ser recuperado para ele e por ele em forma de um serviço de melhor qualidade.

\section{Comentários Finais}

Exemplificaremos as idéias colocadas no texto com algumas conclusões a que chegamos na pesquisa realizada (Minayo ${ }^{10}, 1988$ ) numa área de moradia da população de baixa renda, no subúrbio do Rio de Janeiro. Conforme já esclarecemos, encaminhamos a análise para detectar os estrangulamentos na política de assistência primária à saúde e para o encaminhamento de propostas visando a melhoria do padrão de saúde do grupo social em questão.

Do ponto de vista do diagnóstico, a pesquisa apontou questões ao nível das condições gerais de vida, da orientação para cuidados de saúde e da forma de atuação do centro de saúde: centro de referência para assistência primária. Observamos, por exemplo, que para o grupo de famílias em estado de miséria absoluta e de fome endêmica a política da assistência primária encontra limites que transcendem ao conceito estrito de saúde. O desafio de ultrapassar as barreiras aí encontradas aponta para mudanças que envolvem, além da equipe de saúde, problemas de nivel socioeconômico mais amplos.

Constatamos também que a questão do aleitamento materno é um tema a ser trabalhado através de esclarecimentos e de programas educativos, tendo-se em conta que a diarréia continua a ser a pior inimiga das crianças de 0 a 5 anos na área, particularmente durante o verão, enquanto a pneumonia é a segunda doença em termos de gravidade e incidência.
Em relação ao atendimento realizado na Unidade de referência, a pesquisa indica a importância de uma ação mais integrada com as necessidades concretas da população. E isso só pode ser atingido pela mudança organizacional que leve a equipe de saúde aos locais de moradia, e promova um inquérito epidemiológico com dados primários sobrevindos de fichas realizadas através de visitas domiciliares. Tal mudança poderia ser facilitada se o sistema de saúde integrasse na sua reflexão e programação, as agentes de saúde que atuam na localidade, mas cuja ação sofre um corte de continuidade em relação ao centro de referência.

Há outros pontos detectados que ajudam o encaminhamento das políticas de ação na localidade mas que podem ser aplicados mais amplamente. Notamos, por exemplo, que o grupo de famílias, cuja participação social nas organizações comunitárias é mais intensa, costuma ser privilegiado com os benefícios das políticas sociais. De qualquer forma, é um dado já do domínio dos estudiosos dos estratos sociais de baixa renda, que a participação comunitária supõe um nível mínimo de condições materiais de existência.

Outra constatação também importante em relação à realidade específica é a abertura das famílias em condições mínimas de sobrevivência asseguradas, às contribuições da medicina social. Não significa que suas práticas tradicionais tenham sido superadas. As famílias conseguem fazer uma combinação, a seu modo, entre as práticas médico-científicas e as crenças tradicionais em termos de uso de medicamentos, de chás, ervas, orações e ritos. De qualquer maneira não parece haver contradição, para eles, entre as propostas oficiais e suas práticas domésticas de medicina popular. O ponto de estrangulamento da assistência primária está particularmente nas condições materiais de existência de muitas famílias e na adequação da estrutura funcional da Unidade de referência à realidade da população, para vencer os limites até agora encontrados.

A exposição resumida dos pontos acima, tenta apenas exemplificar a linha de preocupações que, à luz dos dados, podem ser encaminhadas por uma avaliação antropológica. É óbvio que só um tipo de investigação qualitativa consegue levantar as questões que perpassam as diferenças entre as famílias, as contradições internas e os pontos de estrangulamento. E na combinação ou no confronto desses dados com os indicadores oficiais que podemos estabelecer os parâmetros de uma ação mais localizada, mais personalizada e em conjunto com a população a que se destina. 
É necessário lembrar que a abordagem antropológica na avaliação de programas de saúde em si não é neutra. Cada pesquisador, dentro de seu marco teórico e tendo em vista sua própria visão de mundo, influencia tanto o processo investigativo como as conclusões de seu trabalho. A proposta de introduzir a antropologia, sobretudo na avaliação dos serviços, oferece instrumentos importantes para uma atividade que pode se reverter em melhoria do atendimento de saúde das populações-alvo.

Além disso, embora os resultados da pesquisa etnográfica sejam limitados e circunscritos aos grupos pesquisados, - podendo no entanto ser estendidos aqueles em condiçoes socioeconômicas e culturais e acesso aos bens e serviços semelhantes - a abordagem antropológica na avaliação das políticas de saúde poderia ser generalizada. Certamente esse fato demandaria cuidados conceituais e metodológicos especiais. No entanto, sua contribuição daria qualidade aos indicadores sociais geralmente quantitativos e externos à realidade empírica, merecendo-se, portanto, um diálogo interdisciplinar entre antropólogos, sanitaristas e epidemiologistas.

MINAYO, M.C. de S. [An anthropological approach to the evaluation of social policies]. Rev. Saúde públ., S.Paulo, 25:233-8, 1991. A anthropological approach to the evaluation of health programs is presented. A special role is attributed to anthropology which goes beyond its traditional scope as basic research in order to produce, in conjunction with Social Medicine, a particular way of focussing on the evaluation of public policies and, more particularly of health services. Anthropology thus takes its place within a more comprehensive social process to which it contributes with its specific tools for the understanding of reality. Based on empirical research assessment of Primary Health Care in a shanty-town located in Rio de Janeiro (Brazil), it shows that the qualitative method for the evaluation of health programs can contribute greatly to overcoming positivistic trends in the evaluation process as wells as to reaching a more comprehensive perspective for the health-disease phenomenon.

Keywords: Program evaluation. Anthropology. Health policy.

\section{Referências Bibliográficas}

1. BERLINGUER, G. Medicina e política. São Paulo, Hucitec, 1978.

2. BULMER, M. Social policy research. London, Macmillan, 1978.

3. COMMAROFF, J. Medicine and culture: some anthropological perspectives. Soc. Sci. med., 12B: 247-54, 1978.

4. DOUGLAS, M. Natural symbols. New York, Pantheon Books, 1971.

5. DUARTE, L.F. O nervoso na classe trabalhadora. Rio de Janeiro, Zahar Ed., 1986.

6. ESTRELLA, E. As contribuições da antropologia à pesquisa em saúde. In: Nunes, E.D., org. As ciências sociais em saúde na América Latina: tendências e perspectivas. Brasília, Organização Pan-Americana da Saúde, 1985. p. 159-73.

7. LÉVY-STRAUSS, C. Introdução à obra de Marcel Mauss. In: Mauss, M. Sociologia e antropologia. São Paulo, EPU/Ed. USP, 1974. p. 1-36.

8. LOYOLA, M.A. Médicos e curandeiros. São Paulo, DIFEL, 1984.

9. MAUSS, M. Sociologia e antropologia. São Paulo, EPU/Ed. USP, 1974.

10. MINAYO, M.C.S. Avaliação qualitativa da atenção primária à saúde numa favela do Rio de janeiro (RAP). Rio de Janeiro, 1988. Mimeografado.*

11. MINAYO GOMEZ, C. Reflexőes em torno do processo de auto-avaliação institucional. In: Luvisolo, H.R., org. Avaliação em educação de adultos: temas e discussões. Rio de Janeiro, MOBRAL/OREALC, 1984. p. 111-22.

12. MONTERO, P. Da doença à desordem: a magia da umbanda. Rio de Janeiro, Ed. Graal, 1985.

13. NUNES, E.D.,org. As ciências sociais em saúde na América Latina: tendências e perspectivas. Brasilia, Organização Pan-Americana da Saúde, 1985.

14. SCRIMSHAW, S. \& HURTADO, E. Anthropological approaches for programmes improvement. Los Angeles, UCLA, 1987.

Recebido para publicação em 21/3/1990 Aprovado para publicação em 14/3/1991

* Os interessados poderão obter o trabalho diretamente com a autora do presente artigo. 